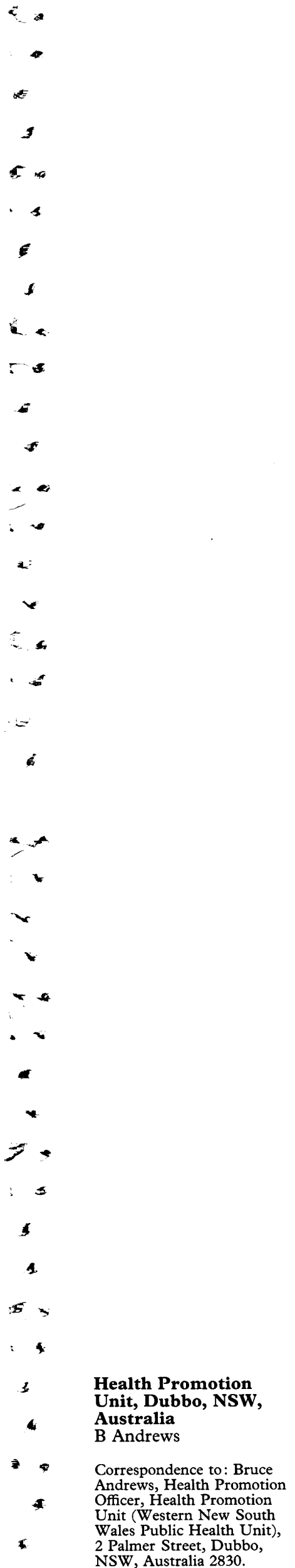

\title{
Patron choice of non-smoking or smoking areas at a large restaurant in rural Australia: a four year study
}

\author{
Bruce Andrews
}

\begin{abstract}
Objective-To monitor and describe patron choice when the offer of nonsmoking and smoking areas is given to patrons when they make a restaurant reservation.
\end{abstract}

Design-A survey of consecutive bookings for 54958 restaurant patrons (more than 12000 annually) at a single restaurant over 4 years (May 1990-April 1994).

Setting - A 140 seat restaurant in Dubbo (population: 35000) in rural New South Wales, Australia.

Main outcome measures - Patron choice of non-smoking or smoking area.

Results-Bookings for the non-smoking area increased from $55.4 \%$ in the first year to $62.3 \%, 66.6 \%$, and $72.6 \%$ each successive year. Each annual increase was statistically significant ( $p<0.001$ ).

Conclusions - A substantial and growing majority of Australian diners will choose to be seated in the non-smoking area of a restaurant if the choice is available to them. It suggests a mismatch between consumer demand and restaurant provision of non-smoking dining, and the inadequacy of aspects of public health policy, regulation, and legislation concerning environmental tobacco smoke in Australia.

(Tobacco Control 1995; 4: 129-131)

Keywords: environmental tobacco smoke; restaurants; smoking; patron choice

\section{Introduction}

After decades of scientific research on the health effects of active smoking, research during the 1980 s about the health effects of passive smoking confirmed that environmental tobacco smoke is a significant health risk to non-smokers. ${ }^{1}$ Scientific ${ }^{2,3}$ and, in Australia, legal $^{4-6}$ substantiation of the health risks to non-smokers from breathing environmental tobacco smoke has continued, along with publicity about health authority concerns.

Despite the recommendation by the National Health and Medical Research Council (of Australia) in June 1986 that "an atmosphere free of tobacco smoke should be regarded as the workplace norm", and that smoking should be restricted or prohibited in all public places, including restaurants, ${ }^{\overline{2}}$ in the state of New South Wales (NSW) the decision whether to restrict smoking in hotels, clubs, and restaurants is still left to the individual owner/operator or manager. Research on behalf of the NSW government Quit Campaign in August 1993 indicated that only $7 \%$ of dining establishments in NSW are completely non-smoking and only $28 \%$ have non-smoking areas. ${ }^{7}$

There have been several studies of the opinions, attitudes, and preferences of the public with regard to smoking in restaurants. These show strong majority support for complete smoking bans or the provision of smokefree areas in restaurants. ${ }^{8-15}$ The extent to which patrons actively seek out or choose smoke-free areas when they are available has been little studied. An earlier report on patron choice found that bookings for the smoke-free area in an NSW restaurant increased from $55 \%$ to $62 \%$ over two years. ${ }^{16}$ This paper reports on trends in patron choice at the same restaurant over four years.

\section{Methods}

In April 1990 the Dubbo-based Health Promotion Unit (HPU) and the Drug and Alcohol Services began a regionwide smoke-free restaurant campaign in what was then the Orana and Far West region of New South Wales. ${ }^{17}$ In conjunction with this campaign the newly renovated 140 seat Rendezvous Restaurant in the Dubbo Memorial Returned Services League (RSL) Club introduced a non-smoking area. The manager also agreed to allow the HPU to monitor the restaurant bookings. The club has a membership of more than 8000 and is the largest social and recreational organisation in Dubbo (population: 35000). The restaurant is open on four nights each week, Wednesday to Saturday, to members, visitors, and the general public.

Reception staff who took the restaurant bookings were instructed to ask all patrons who made a booking whether they wished to be seated in the non-smoking or smoking area, and how many there would be in each party. The bookings were later tallied by restaurant staff and entered daily on a separate form which was collected by the HPU at the end of each calendar month. The HPU tallied the weekly and monthly bookings and provided a 
summary report to the club manager for each month. Reception staff report that there has rarely been any confusion or uncertainty on the part of patrons when they are asked to choose the area in which they wish to dine. Club staff and management estimate that approximately $95 \%$ of all the restaurant patrons make an advance booking by phone or in person at the foyer reception desk; that is, only about $5 \%$ of patrons arrive at the restaurant without a booking.

The restaurant non-smoking area occupies about two thirds of the seating, and the smoking area occupies about one third of the seating. There is no partition separating the two areas in the restaurant though some potted plants indicate a boundary. No signs or symbols are displayed in the restaurant to distinguish the non-smoking and smoking areas. There was no change in the proportion of space or the number of seats in the nonsmoking or the smoking areas during the four years. Restaurant staff report that there has never been any transgression or problem.

\section{Results}

Bookings for the non-smoking area increased from $55.4 \%$ in the first year to $62.3 \%, 66.6 \%$, and $72.6 \%$ each successive year (table). Each annual increase was statistically significant ( $p$ $<0.001$ )

\section{Discussion}

Although this is a study of only one restaurant, the data appear to show majority support for smoke-free dining which is increasing. The findings are in accord with community preferences identified by other studies that were based on major metropolitan populations, ${ }^{8-15}$ and seem to substantiate the recent Australian surveys that found that the majority of respondents were bothered by environmental tobacco smoke ${ }^{18}$ and found it annoying. ${ }^{19}$ Here we can see that, when given the choice, most restaurant patrons will choose to avoid dining in smoking areas.

I make no claim for a causal relationship between these findings and any particular local intervention during the period of the study. Rather, the growth in demand for the nonsmoking area is a manifestation of the "quite complex different configurations of tobacco control activity" 20 which characterise contemporary Australia.

Table 1990-94 Yearly total and non-smoking bookings (No and percent)

\begin{tabular}{lcccc}
\hline Year & $\begin{array}{c}\text { Total } \\
\text { bookings }\end{array}$ & $\begin{array}{c}\text { Non- } \\
\text { smoking } \\
\text { bookings } \\
(\text { No })\end{array}$ & $\begin{array}{c}\text { Non- } \\
\text { smoking } \\
\text { bookings } \\
(\%)\end{array}$ & $\%$ Increase \\
\hline $1990 / 91$ & 14598 & 8085 & $55.4 \%$ & - \\
$1991 / 92$ & 13772 & 8574 & $62.3 \%$ & $\left.\begin{array}{c}6.9 \% \\
(\mathrm{p}<0.001) \\
4.3 \%\end{array}\right)$ \\
$1992 / 93$ & 12920 & 8599 & $66.6 \%$ & $\left.\begin{array}{c}4.3 \% \\
(\mathrm{p}<0.001) \\
6.0 \%\end{array}\right)$ \\
$1993 / 94$ & 13668 & 9921 & $72.6 \%$ & $(\mathrm{p}<0.001)$ \\
Total & 54958 & 35179 & $64 \%$ & - \\
\hline
\end{tabular}

During the four years of this study there was annual publicity about World No-Tobacco Day (May 31st) and Quit Week, other specific smoking and health campaigns, and controversy about the extension of tobacco advertising bans and smoking bans on domestic airlines, as well as three Australian court cases which focused on passive smoking. ${ }^{4-6}$ The prohealth decisions in each court case were widely publicised as significant legal precedents at the time, and they contributed to and reinforced public awareness about the health hazards of passive smoking and calls for preventive action.

When considered with the "demand/ provision" mismatch identified in Australia ${ }^{14}$ and in Ireland, ${ }^{21}$ and with the other preference studies already noted, these data suggest the failure of most of the hospitality industry to understand, acknowledge, and accommodate a public which has changed its attitudes and behaviour toward smoking. Non-smoking is, after all, majority behaviour in Australia. ${ }^{22}$

This study also covers the period during which the Australian economy underwent its worst recession in 60 years. The data show that despite the decline in total bookings during 1992 and 1993, the number of non-smoking bookings, in absolute and relative terms, increased throughout this recession period. It is possible that, as high unemployment and interest rates impinged on the community, and with cigarettes costing approximately $\$ A 5.00$ per pack (ie, \$A35 per week, about the cost of a restaurant meal), smokers opted to spend their limited disposable income to sustain their addiction rather than dine out. The ironic lesson for restaurateurs here seems to be that, during hard economic times at least, it is nonsmokers who are more likely to maintain their restaurant patronage than the smokers for whom they presently over-cater.

As a public health and an occupational health and safety issue, hospitality industry self-regulation concerning environmental tobacco smoke is a temporary experiment which, for the bulk of the industry, appears to be failing. Perhaps further research is necessary to determine whether this is largely due to a perception that "smoke-free" equates with economic loss, a proposition debunked in the US by Glantz and Smith. ${ }^{23}$

The recent release of a "Guidance note on passive smoking in the workplace" by the federal government agency WorkSafe Australia is unlikely to prompt any greater immediate protection from environmental tobacco smoke for patrons and staff than currently exists. This guidance note was issued instead of draft national legislation or even a compromise (yet more legally binding) "code of practice" because of industry pressure. ${ }^{24}$ Consequently, increased protection from environmental tobacco smoke is likely to result only from the slow accumulation of successful passive smoking litigation. This costly, time consuming, but necessary legal process must now be encouraged and resourced by the health sector.

The hospitality industry's blinkered re- 
course to catch phrases such as "market forces" (in reality, overcatering to a minority market segment) and "freedom of choice" (when none is offered by most establishments) is a shallow response to legitimate public health concerns. Such a stance does nothing for non-smoking patrons, or for non-smoking staff who, through workplace environmental tobacco smoke exposure, have been shown to be "light smokers" 25 and to have an estimated excess lung cancer risk of more than $30 \%$ (compared with unexposed non-smokers in domestic settings). ${ }^{26}$

It is regrettable that, with such a high level of community support on this issue, Australian governments (with the exception of the Australian Capital Territory) remain so reluctant to introduce the smoking control legislation which many in the hospitality industry (as distinct from industry associations) have suggested would provide the compulsory smoke-free "level playing field" that they want, ${ }^{14,17,27}$ and the smoke-free restaurants which the majority of Australians seem to want.

This study is based on a presentation at the 9th World Conference on Tobacco and Health, Paris, France, October 1994. The co-operation and assistance of the management and staff of Dubbo Memorial RSL Club is gratefully acknowledged, as is the assistance of colleagues Srimal Abeysekera, Andrew
Phillips, Catherine Mahon, and Andrew Hahn with the statistical analysis and presentation of these data.

1 US Department of Health and Human Services. The health consequences of involuntary smoking : a report of the US consequences of involuntary smoking: a report of the US Surgeon General, 1986. Rockville, Maryland: Public (DHHS publication No (CDC) 87-8398.)

2 National Health and Medical Research Council (Australia) Report of the working party on the effects of passive smoking on health. Canberra: Australian Government Printing Service, 1987: 53 .

3 US Environmental Protection Agency. Respiratory health effects of passive smoking: lung cancer and other disorders. Washington DC: Office of Health and Environmental Assessment, 1992. (Publication No EPA/600/690/006F.)

4 Australian Federation of Consumer Organisations Inc $v$ The Tobacco Institute of Australia Ltd (1991) 30 FCR 548 (Justice Morling)

5 Australian Federation of Consumer Organisations Inc $v$ Tobacco Institute of Australia Ltd (1991) NG217, Federal Court of Australia (Justices Sheppard, Hill, and Foster), 10th March 1993
6 Scholem $v$ NSW Health Department, NSW District Court, Sydney (Justice Graham), 27th May 1992.

7 Giezen A. Restaurants and smoking : a report on a benchmark survey of restaurants, pubs and clubs. North Sydney NSW: survey of restaurants, pubs and clubs.

8 Hill D. Public opinion about smoking in restaurants and at work [letter]. Med f Aust 1986; 145: 657-8.

9 Hill D, Grey N. Australian patterns of tobacco smoking and related health beliefs. Community Health Stud 1984; 8 : 307-15.

10 Wakefield $M$, Roberts L. Public opinion about smoking restrictions in dining establishments. In: South Australian smoking and health project evaluation report 1990-1991. Adelaide: The Project, 1991.

11 Clark $\mathrm{K}$, Brown $\mathrm{H}$. Public attitudes towards smoking in restaurants, 1984-1987. Paper presented to the Public Health Association of Australia and New Zealand Conference, Sydney, August 1987. Perth: Health Department of WA, Health Promotion Services Branch, 1987.

12 Borland R, Hill D. Public attitudes to smoke-free zones in restaurants: an update [letter]. Med $\mathcal{F}$ Aust 1991; 154 292-3.

13 Roberts C, Algert C, Chey T, Capon A, Gray E. Community attitudes to smoking in restaurants [letter] Med f Aust 1992; 157: 210 .

14 Schofield MJ, Considine R, Boyle CA, Sanson-Fisher RW Smoking control in restaurants: the effectiveness of self regulation in Australia. Am $\mathcal{F}$ Public Health 1993; 83 1284-8.

15 McAllister I. Public opinion in Australia on restricting smoking in public places. Tobacco Control 1995; 4 30-35.

16 Andrews B. Demand for smoke-free dining [letter]. Med $\mathcal{F}$ Aust 1992; 157: 713 .

17 Andrews B, Rosser C. Smoke-free restaurant campaign [unpublished report]. Dubbo: Orana and Far West [unpublished report]. Dubbo: Orana and Far

18 Borland R, Mullins R. How bothered are people by environmental tobacco smoke? Med f Aust 1994; 160 585 .

19 McAllister I, Goodin M. Public opinion of environmental tobacco smoke. Med $\mathcal{f}$ Aust 1994; $161: 231$

20 Chapman S. Unravelling gossamer with boxing gloves: problems in explaining the decline in smoking. $B M \mathcal{F}$ 1993; 307: 429-32.

21 McArdle M, Kelleher CC, Ward JJ. Consumer choice and Ireland's tobacco regulations: do restaurateurs meet their client's needs? Health Promotion International 1993; 8(4): 275 .

22 Australian Bureau of Statistics, Canberra: 1989-90 National Health Survey, Smoking, Australia.

23 Glantz SA, Smith LR. The effect of ordinances requiring smoke free restaurants on restaurant sales in California. School of Medicine, University of California, San Francisco: Institute for Health Policy Studies, March 1992.

24 National Occupational Health and Safety Commission. Guidance note on passive smoking in the workplace. Canberra: Australian Government Publishing Service, July 1994. [NOHSC: 3019(1994).]

25 Tutt D, Harris W. Where there's smoke... Carbon monoxide exposures in smoking and smoke-free workplaces. Community Health Stud 1990; 14(3): 297-302.

26 Siegal $M$. Involuntary smoking in the restaurant workplace a review of employee exposure and health effects. $\mathcal{F} A M A$ $1993 ; 270: 490-3$

27 Turner J. Smoke-free hospitality project report. Hospitality Industry Smoking Policy Committee, Adelaide, 1993: 33. 